Annals of the University of Craiova

The Chemistry Series

Volume XLVII, No. 2 (2021) 45-52

homepage: chimie.ucv.ro/anale/

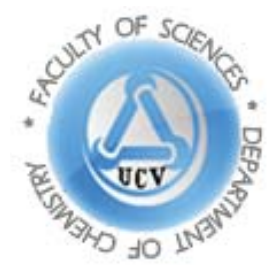

\title{
Total phenolic, total flavonoids content and antioxidant activity in fruits of four plum (Prunus domestica l.) cultivars
}

\section{Research article}

\section{Cristina Băbeanu ${ }^{1}$, Andi Ciobanu*}

${ }^{1}$ University of Craiova, Faculty of Sciences, Department of Chemistry, Calea București 107i, Craiova, Romania

${ }^{2}$ University of Craiova, Faculty of Agriculture, 19 Libertatii Street, Craiova, Romania

*E-mail: andi.ciobanu@yahoo.com

Received: 25.09.2021 / Accepted: 28.10.2021 / Published: 27.12.2021

\begin{abstract}
Plums are among the most consumed fruits in Romania, being a good source of health promoting compounds. The objective of this paper is to evaluate in comparison the total phenolic content, the flavonoids and anthocyanins content and antioxidant activity in fruit of four plum cultivars. The total phenolic, flavonoids and anthocyanin contents were determined by colorimetric methods and the antioxidant activity was evaluated by DPPH radical scavenging assay. The results show that studied chemical indices vary depending on the analyzed cultivar. The obtained results show that all the studied cultivars show a high phytochemicals content and significant antioxidant activity and recommend their use as sources of phenolic compounds and natural antioxidants.
\end{abstract}

Keywords: plum, phenolic compounds, flavonoids, anthocyanins, antioxidant activity

DOI: 10.52846/AUCCHEM.2021.2.05 


\section{INTRODUCTION}

Plums, the most consumed fruits in Romania, are a good source of bioactive compounds. Plums contain organic acids, carbohydrates, fibers, pectins, aromatic substances, tannins, enzymes, phenolic compounds, flavonoids, anthocyanins, vitamins (A, C, K, B complex, E, folate) and minerals such as: potassium, phosphorus, calcium magnesium, iron and zinc [1-3]. Epidemiological studies have shown that plums can treat and prevent digestive diseases, cancer, diabetes, obesity [4,5]. Such beneficial effects are explained by their content in antioxidant activity compounds [1] which scavenge and inhibit the reactions of free radicals and protect the cell against oxidative damage.

Physico-chemical characteristics vary with cultivar, environmental conditions and agricultural practices [6]. The increase of qualitative and quantitative productivity is ensured by the cultivation of genotypes that have been identified and selected as resistant to biotic and abiotic stress $[7,8]$.

The purpose of this study was to determine the phytonutrient content and the antioxidant activity in four plum cultivars in order to identify those with high nutritional qualities.

\section{MATERIALS AND METHODS}

\subsection{Materials}

The biological material was represented by fruits of four cultivars of plum: Tuleu timpuriu, Centenar, Tuleu gras and Stanley, grown in private orchard in Olt county. All the plum cultivars were grown under the same horticultural practices. Samples from the cultivars were harvested in their technological ripening stage and immediately after the harvest was determined total phenolic, total flavonoids and total anthocyanin content and antioxidant activity. 


\subsection{Analysis methods}

Sample preparation: For the determination of investigated biochemical indices, samples were extracted with $80 \%$ aqueous methanol with $1 \% \mathrm{HCl}(1: 20 \mathrm{w}: \mathrm{v})$ by sonicating for $60 \mathrm{~min}$ in a sonicator bath Fungilab (Madrid, Spain) equipped with a digital timer and a temperature controller at $24^{\circ} \mathrm{C}$. The resulting slurries were centrifuged at $4000 \mathrm{~g}$ for $5 \mathrm{~min}$ and the supernatants were collected.

Total phenolic compounds (TPC) content was determined colorimetric by using the Folin-Ciocalteu method [9] based on the oxidation of phenolic groups with phosphomolybdic and phosphotungstic acids. $2 \mathrm{~mL}$ Folin-Ciocalteu's phenol reagent (1:10) and $1.5 \mathrm{~mL} 7.5 \% \mathrm{w} / \mathrm{v} \mathrm{Na}_{2} \mathrm{CO}_{3}$ were added to $0.5 \mathrm{~mL}$ sample extract. The mixture was allowed to stand at room temperature in the dark for 60 min and then the absorbance was recorded at $765 \mathrm{~nm}$. The total phenolic content (TPC) was calculated using a standard curve prepared using gallic acid and expressed as mg of gallic acid equivalents (GAE)/100 g fw (fresh weight).

The total flavonoids (TF) content was quantitatively determined by colorimetric method at $500 \mathrm{~nm}$ [9]. $0.5 \mathrm{~mL}$ of the sample extract was transferred into a $10 \mathrm{~mL}$ volumetric flask. Furthermore, a $0.6 \mathrm{~mL}$ of $5 \%$ sodium nitrite $\left(\mathrm{NaNO}_{2}\right)$ was added and the mixture was shaken and left for $6 \mathrm{~min}$. $0.5 \mathrm{~mL}$ of $10 \% \mathrm{Al}\left(\mathrm{NO}_{3}\right)_{3}$ was added to the volumetric flask, shaken, and left to stand for $6 \mathrm{~min}$. Finally, $3.0 \mathrm{~mL}$ of the $4.3 \% \mathrm{NaOH}$ was added to the volumetric flask. Subsequently, water was added up to the scale. The mixture was then shaken and left to stand for $15 \mathrm{~min}$ before determination. The total flavonoid concentration in methanol extract was calculated from quercetin calibration curve and expressed as quercetin equivalents $\mathrm{mgQE} / 100 \mathrm{~g}$ f.w.

Total anthocyanin content (TA) was measured by the $\mathrm{pH}$ differential method [10] Sample extracts were diluted with potassium chloride and with sodium acetate buffers ( $\mathrm{pH} 1.0$ and 4.5, respectively) and after an equilibration period, absorbance of each solution was measured at 520 and $700 \mathrm{~nm}$. The absorbance value was calculated as $\mathrm{A}=[(\mathrm{A} 520$ - A700) pH 1.0 - (A520 - A700) pH 4.5]. 
The result, considered as the total anthocyanins content, was calculated as $\mathrm{mg}$ of cyanidin-3-glucoside equivalents (CE)/100 $\mathrm{g} \mathrm{fw}$ by using a molar extinction coefficient of 26900 and molecular weight of 449,2 [11].

DPPH (2,2-diphenyl-1-picrylhydrazyl) radical scavenging assay: The capacity of sample extracts to reduce the radical 2,2-diphenyl-1picrylhydrazyl has been evaluated colorimetrically [10]. $2 \mathrm{~mL}$ of 0.075 $\mathrm{mM}$ DPPH solution in methanol was mixed with $0.1 \mathrm{~mL}$ sample extract and after 20 minutes the absorbance of the remaining DPPH radicals was measured at $517 \mathrm{~nm}$. The normal color of DPPH will turn into yellow when its singlet electron is paired with a hydrogen atom coming from a potential antioxidant. A blank reagent was used to study stability of DPPH over the test time. The scavenging activity of extracts was evaluated as a percentage of DPPH discoloration using the formula: $\%$ scavenging $=[\mathrm{A} 0-(\mathrm{A} 1-\mathrm{AS})] / \mathrm{A} 0] 100$, where A0 is the absorbance of $\mathrm{DPPH}$ alone, A1 is the absorbance of DPPH + extract and AS is the absorbance of the extract only. The results values were compared with those obtained from standard curves of trolox and ascorbic acid. Antioxidant capacity values were expressed as trolox equivalents $(\mu \mathrm{M}$ $\mathrm{TE} / 100 \mathrm{~g} \mathrm{fw}$ ) or ascorbic acid equivalents ( $\mu \mathrm{M}$ AsA/100g fw).

The spectrophotometric measurements were performed with a Thermo Scientific Evolution $600 \mathrm{UV}-\mathrm{Vis}$ spectrophotometer with VISION PRO software. All determinations were performed in triplicate, and all results were calculated as mean.

\section{RESULTS AND DISCUSSION}

The obtained results show that studied chemical indices vary depending on the analyzed cultivar.

The content of total phenolic compounds (TPC) varies between 278.35 mgGAE/100g fw (Tuleu gras) and 451.34 mgGAE/100g fw (Tuleu Timpuriu) in the order: Tuleu Gras < Stanley < Centenar < Tuleu Timpuriu (Figure 1). The data obtained in this study are similar to those presented by other researchers. In a study presenting chemical characteristics of commercial cultivars of plum trees, TPC values are reported ranging from 3.48 -4.95 mg GAE g-1 FM [12]. Cevallos-Casals 
et al., 2006 reported that in plums genotypes, phenolic content ranged from 298 to $563 \mathrm{mg}$ of GAE/100 $\mathrm{g}$ [13].

Many authors reported different results in TPC. Values in the range of 174.0 to $375.0 \mathrm{mg}$ GAE/100 g are reported for six cultivars [14]; 86 to 413 $\mathrm{mg}$ GAE/100 g among the 20 genotypes of European plums [15]; 2.63 to $9.93 \mathrm{mg}$ GAE /g for sixteen plum genotypes [2]. A wide spectrum of phenols has been identified in plums. Usenik et al., 2008 finds that in plum fruits neochlorogenic acid was the major hydroxycinnamic acid derivative, followed by chlorogenic acid, rutin, and p-coumaroylquinic acid [1].

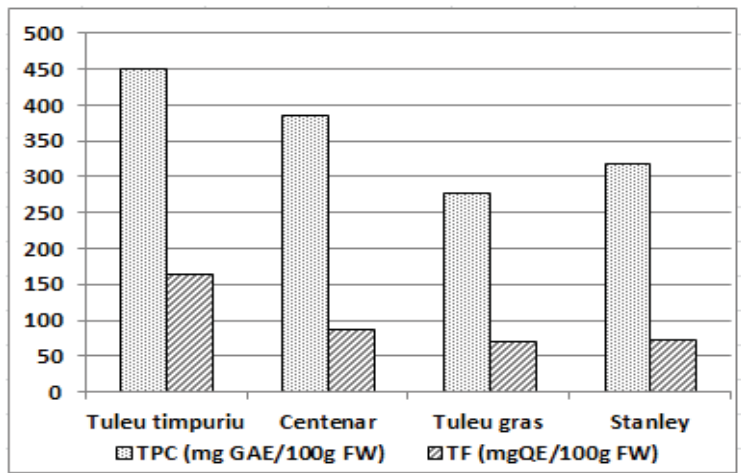

Figure 1. Total phenolic content (TPC) and total flavonoids content (TF) in studied plum cultivars

The content of total flavonoids compounds (TF) varies between 71.18 mgQE/100g fw (Tuleu gras) and $164.13 \mathrm{mgQE} / 100 \mathrm{~g}$ fw (Tuleu Timpuriu). The content of flavonoid compounds increases in the order of Tuleu Gras < Stanley <Centenar $<$ Tuleu Timpuriu (Figure 1).

The results obtained in our study are similar to data reported by other authors. For total flavonoid content for six plum varieties is reported values between 118 and $237 \mathrm{mg}$ catechin equivalents /100 g [14].

Total anthocian content (TA), varies between 46,35 and 108.2 $\mathrm{mgCE} / 100 \mathrm{~g} \mathrm{fw}$ as follows: Tuleu gras $(46,35 \mathrm{mg} \mathrm{CE} / 100 \mathrm{~g} \mathrm{fw})<$ Centenar $(58,12 \mathrm{mgCE} / 100 \mathrm{~g} \mathrm{fw})<$ Stanley $(83,24 \mathrm{mgCE} / 100 \mathrm{~g} \mathrm{fw})<$ Tuleu Timpuriu (108.2 $\mathrm{mgCE} / 100 \mathrm{~g} \mathrm{fw})$ The results obtained are shown in Figure 2.

In the scientific literature, large differences are reported between cultivars regarding the content in anthocyanins. For sixteen plum genotypes growing in Pakistan, total anthocyanin content ranged 
between $14.23 \mathrm{mg} / 100 \mathrm{~g}$ and la $212.38 \mathrm{mg} / 100 \mathrm{~g}$ [2]. For fruits of plum Stanley, harvested five times per year, total anthocyanins content ranged from 5 to $57 \mathrm{mg} / 100 \mathrm{~g}$ [16].

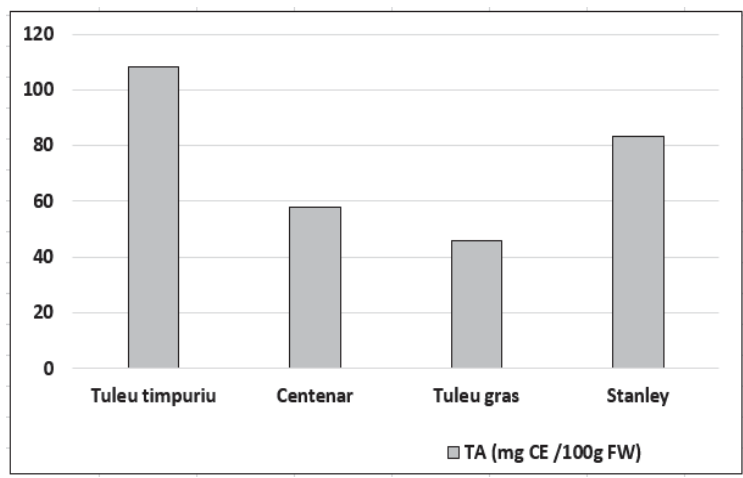

Figure 2. Total antocyanin content (TA) in studied plum cultivars

For fruits of twelve plum cultivars grown in Rm Valcea area, the values for total anthocyanins content ranged between $0.41 \mathrm{mg} / 100 \mathrm{~g}$ and $198.89 \mathrm{mg} / 100 \mathrm{~g}$ [17]. Cevallos Casals, 2006 reports total anthocyanin content values ranging from $33 \mathrm{mg} / 100 \mathrm{~g}$ to $173 \mathrm{mg} / 100 \mathrm{~g}$ [13].

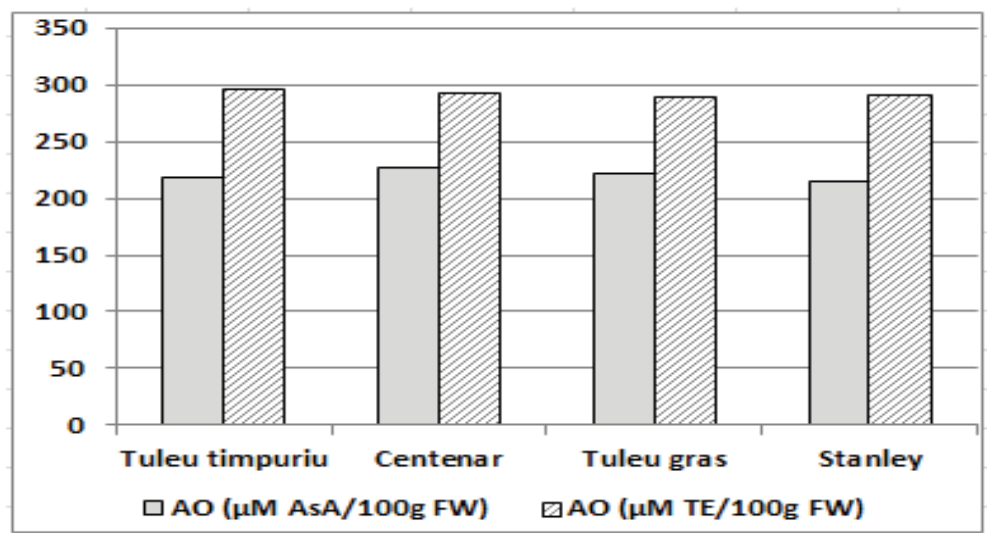

Figure 3. Antioxidant activity $(\mathrm{AO})$ of studied plum cultivars

Antioxidant activity. It is well known that the results for the determination of antioxidant activity are influenced by radical system used. In this study antioxidant activity of the studied plum cultivars was determined by the ability of extracts to scavenge the DPPH radical. The results obtained are shown in Figure 3. 
The values of DPPH radical scavenging activity, express as ascorbic acid equivalents ranged from $214 \mu \mathrm{MAscA} / 100 \mathrm{~g}$ f.w. (Stanley) to $236 \mu \mathrm{MAscA} / 100 \mathrm{~g}$ f.w. (Tuleu Timpuriu) and decreased as follows: Tuleu Timpuriu $>$ Centenar $>$ Tuleu gras $>$ Stanley.

The obtained results for DPPH radical scavenging activity express as Trolox equivalents ranged from $288 \mu \mathrm{MTE} / 100 \mathrm{~g}$ f.w. (Tuleu Gras) to $296 \mu \mathrm{MTE} / 100 \mathrm{~g}$ f.w. (Tuleu Timpuriu) and decreased as follows: Tuleu Timpuriu >Centenar $>$ Stanley $>$ Tuleu gras. In our previous investigations on the same plum cultivars the same variation is observed for the content of vitamin $C$, powerful antioxidant compound [3]. Some researchers have shown that among the compounds with antioxidant properties in fruit, it seems that antioxidant activity is greatly influenced by the content of phenolic compounds and less by vitamin C and carotenoids [13,18].

Positive correlations have been observed when DPPH radical scavenging activities were compared with total phenolic compounds content and total flavonoids content, thus indicating that these compounds are responsible for the antioxidant activity. This positive correlation was also reported for other plant species $[9,10]$.

\section{CONCLUSION}

The obtained results show that studied biochemical indices vary depending on the analyzed cultivar.

High bioactive compounds content, with an important role in human health and high antioxidant activity were reported for all investigated cultivars and the results recommend their use as sources of phenolic compounds and natural antioxidants.

Positive correlations have been observed when DPPH radical scavenging activities were compared with total phenolic compounds content and total flavonoids content, thus indicating that these compounds are responsible for the antioxidant activity.

The study put into the light the nutritional qualities of Tuleu Timpuriu plum cultivar with the highest phytochemicals content and antioxidant activity. 


\section{REFERENCES}

1. V. Usenik, D. Kastelec, R. Veberic and F. Štampar, Food Chemistry, 111 (2008) 830.

2. H. Nisar, M. Ahmed, M.A. Anjum and S. Hussain, Acta Sci. Pol. Hortorum Cultus, 14(1) (2015) 45.

3. C. Babeanu and A. Ciobanu, Annals of the University of Craiova-Agriculture, Montanology, Cadastre Serie, 50 (1) (2020) 7.

4. S. Hooshmand and B.H. Arjimani, Aging Res. Rev., 8 (2009) 122.

5. D. Walkowiak-Tomczak, Pol. J. Food Nutr. Sci., 58 (4) (2008) 401.

6. A. Ciobanu, Annals of the University of Craiova-Agriculture, Montanology, Cadastre Series, 47 (2017) 95.

7. E. Bonciu, Annals of the University of Craiova-Agriculture, Montanology, Cadastre Series, 47(1) (2017) 391.

8. E. Bonciu, Annals of the University of Craiova-Agriculture, Montanology, Cadastre Series, 49(1) (2019) 36.

9. R. Soare, C. Babeanu, D. Bonea and O. Panita, Scientific Papers-Series A, Agronomy, 58 (2015) 307.

10. R. Soare, M. Dinu, C. Babeanu and M. Soare, Plant, Soil and Environment, 66(6) (2020) 281.

11. M.M. Giusti and R.E. Wrolstad, Journal of Food Science, 61 (1996) 688.

12. O. Rop, T. Jurikova, J. Mlcek, D. Kramarova and Z. Sengee, Scientia Hort., 122(4) (2009) 545.

13. B.A. Cevallos-Casals, D. Byrne, W.R. Okie and L. Cisneros-Zevallos, Food Chem., 96 (2006) 273.

14. D.O. Kim, S.W. Jeong and C.Y. Lee, Food Chem., 81 (2003) 321.

15. H.P.V. Rupasinghe, DS. Jayasankar and W. Lay, Sci. Horticult., 108 (2006) 243.

16. N. Miletić, B. Popović, O. Miletić and M. Kandić, Australian Journal of Crop Science, 6(4) (2012) 681.

17. M.E. Ionica, V. Nour, I. Trandafir, S. Cosmulescu and M. Botu, Not Bot Horti Agrobo., 41(2) (2013) 499.

18. M. I. Gil, F.A. Tomas-Barberan, B. Hess-Pierce, and A.A. Kader, J. Agric. Food Chem., 50 (2002) 976. 